\title{
Characteristics and outcomes of COVID-19 patients with COPD
}

\section{from the United States, South Korea, and Europe [version 1;}

\section{peer review: 1 approved with reservations]}

\section{David Moreno-Martos (D1, Katia Verhamme², Anna Ostropolets (iD), Kristin Kostka4,5, Talita Duarte-Sales ${ }^{6}$, Daniel Prieto-Alhambra7, Thamir M Alshammari8, Heba Alghoul (D), Waheed-Ul-Rahman Ahmed7,10, Clair Blacketer 2,11, Scott DuVall12, Lana Lai13, Michael Matheny ${ }^{14,15}$, Fredrik Nyberg (Did), Jose Posada (D)17, Peter Rijnbeek2, Matthew Spotnitz (iD)3, Anthony Sena2,11, Nigam Shah17, Marc Suchard (D)18,19, Seng Chan You (D)20, George Hripcsak³, Patrick Ryan3,11, Daniel Morales (iD)1,21}

\footnotetext{
${ }_{1}^{1}$ Population Health and Genomics, University of Dundee, Dundee, UK

${ }^{2}$ Medical Informatics, Erasmus MC, Rotterdam, The Netherlands

${ }^{3}$ Biomedical Informatics, Columbia University Medical Center, New York, USA

${ }^{4}$ Real World Solutions, IQVIA, Cambridge, MA, USA

${ }^{5}$ OHDSI Center at The Roux Institute, Northeastern University, Portland, ME, USA

${ }^{6}$ Fundació Institut Universitari per a la recerca a l'Atenció Primaria de Salut Jordi Gol i Gurina (IDIAPJGol), IDIAPJGol, Barcelona, Spain

${ }^{7}$ Nuffield Department of Orthopaedics, Rheumatology, and Musculoskeletal Sciences, University of Oxford, Oxford, UK

${ }^{8}$ College of Pharmacy, Riyadh Elm University, Riyadh, Saudi Arabia

${ }^{9}$ Faculty of Medicine, Islamic University of Gaza, Gaza, Palestinian Territory

${ }^{10}$ College of Medicine and Health, University of Exeter, Exeter, UK

${ }^{11}$ Janssen Research and Development, Janssen Research and Development, Titusville, NJ, USA

${ }^{12}$ VA Informatics and Computing Infrastructure, University of Utah, Salt Lake City, UT, USA

${ }^{13}$ Department of Medical Sciences, University of Manchester, Manchester, UK

${ }^{14}$ Geriatrics Research Education and Clinical Care Service \& VINCI, Tennessee Valley Healthcare System VA, nashville, TN, USA

${ }^{15}$ Department of Biomedical Informatics, Vanderbilt University Medical Center, Nashville, TN, USA

${ }^{16}$ School of Public Health and Community Medicine, University of Gothenburg, Gothenburg, Sweden

${ }^{17}$ Department of Medicine, Stanford University, Redwood City, CA, USA

${ }^{18}$ Department of Biostatistics UCLA Fielding School of Public Health, University of California, Los Angeles, Los Angeles, CA, USA

${ }^{19}$ Department of Computational Medicine David Geffen School of Medicine at UCLA, University of California, Los Angeles, Los Angeles, CA, USA

${ }^{20}$ Department of Preventive Medicine, Yonsei University, Seoul, South Korea

${ }^{21}$ Department of Public Health, University of Southern Denmark, Odense, Denmark
}

V1 First published: 24 Jan 2022, 7:22

https://doi.org/10.12688/wellcomeopenres.17403.1

Second version: 24 Mar 2022, 7:22

https://doi.org/10.12688/wellcomeopenres.17403.2

Latest published: 10 Jan 2023, 7:22

https://doi.org/10.12688/wellcomeopenres.17403.3

Abstract

Background: Characterization studies of COVID-19 patients with

\section{Open Peer Review}

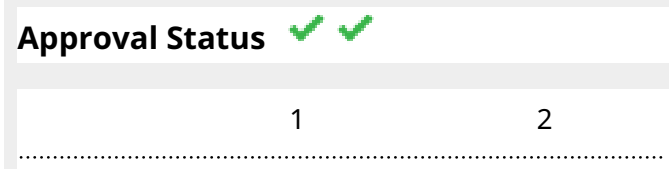

version 3 
chronic obstructive pulmonary disease (COPD) are limited in size and scope. The aim of the study is to provide a large-scale characterization of COVID-19 patients with COPD.

Methods: We included thirteen databases contributing data from January-June 2020 from North America (US), Europe and Asia. We defined two cohorts of patients with COVID-19 namely a 'diagnosed' and 'hospitalized' cohort. We followed patients from COVID-19 index date to 30 days or death. We performed descriptive analysis and reported the frequency of characteristics and outcomes among COPD patients with COVID-19.

Results: The study included 934,778 patients in the diagnosed COVID19 cohort and 177,201 in the hospitalized COVID-19 cohort. Observed COPD prevalence in the diagnosed cohort ranged from 3.8\% (95\% CI 3.5-4.1\%) in French data to $22.7 \%(95 \%$ CI $22.4-23.0)$ in US data, and from $1.9 \%(95 \%$ CI 1.6-2.2) in South Korean to $44.0 \%$ (95\%CI 43.1-45.0) in US data, in the hospitalized cohorts. COPD patients in the hospitalized cohort had greater comorbidity than those in the diagnosed cohort, including hypertension, heart disease, diabetes and obesity. Mortality was higher in COPD patients in the hospitalized cohort and ranged from 7.6\% (95\%CI 6.9-8.4) to 32.2\% (95\%CI 28.036.7) across databases. ARDS, acute renal failure, cardiac arrhythmia and sepsis were the most common outcomes among hospitalized COPD patients.

Conclusion: COPD patients with COVID-19 have high levels of COVID19-associated comorbidities and poor COVID-19 outcomes. Further research is required to identify patients with COPD at high risk of worse outcomes.

\section{Keywords}

COPD, SARS-CoV-2, coronavirus, COVID, epidemiology.

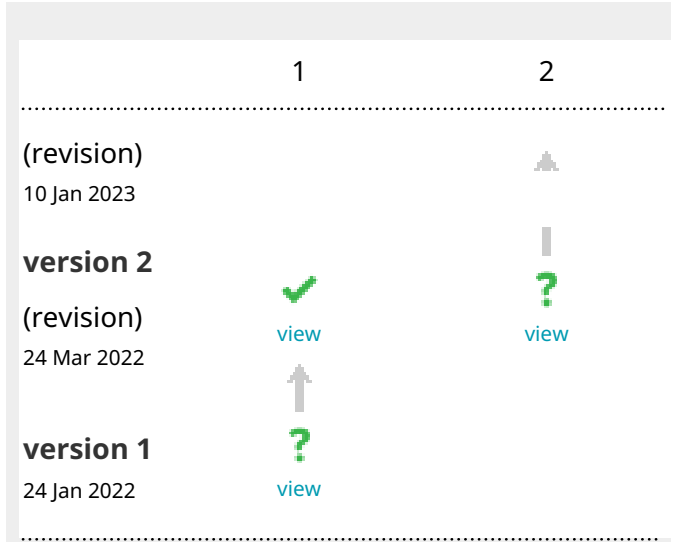

1. Marta A. Kisiel, Uppsala University, Uppsala,

Sweden

2. Laurie Tomlinson (D), London School of

Hygiene \& Tropical Medicine, London, UK

Any reports and responses or comments on the article can be found at the end of the article.

\section{Corresponding author: Daniel Morales (d.r.z.morales@dundee.ac.uk)}

Author roles: Moreno-Martos D: Formal Analysis, Investigation, Project Administration, Software, Validation, Visualization, Writing Original Draft Preparation, Writing - Review \& Editing; Verhamme K: Data Curation, Investigation, Methodology, Supervision, Writing Original Draft Preparation, Writing - Review \& Editing; Ostropolets A: Conceptualization, Data Curation, Investigation, Methodology, Software, Visualization, Writing - Review \& Editing; Kostka K: Conceptualization, Data Curation, Formal Analysis, Investigation, Methodology, Project Administration, Resources, Software, Supervision, Validation, Visualization, Writing - Original Draft Preparation, Writing - Review \& Editing; Duarte-Sales T: Conceptualization, Data Curation, Formal Analysis, Investigation, Methodology, Project Administration, Resources, Software, Supervision, Validation, Visualization, Writing - Original Draft Preparation, Writing - Review \& Editing; Prieto-Alhambra D: Conceptualization, Funding Acquisition, Investigation, Methodology, Project Administration, Resources, Software, Supervision, Writing - Review \& Editing; Alshammari TM: Conceptualization, Investigation, Methodology, Supervision, Writing - Review \& Editing; Alghoul H: Investigation, Methodology, Writing - Review \& Editing; Ahmed WUR: Investigation, Methodology, Writing - Review \& Editing; Blacketer C: Data Curation, Investigation, Methodology, Project Administration, Resources, Software, Validation, Writing - Review \& Editing; DuVall S: Data Curation, Investigation, Methodology, Project Administration, Resources, Software, Validation, Writing - Review \& Editing; Lai L: Formal Analysis, Investigation, Methodology, Writing - Review \& Editing; Matheny M: Data Curation, Investigation, Methodology, Project Administration, Resources, Software, Supervision, Writing - Review \& Editing; Nyberg F: Investigation, Methodology, Supervision, Writing - Review \& Editing; Posada J: Data Curation, Investigation, Methodology, Project Administration, Writing - Review \& Editing; Rijnbeek P: Conceptualization, Funding Acquisition, Investigation, Methodology, Project Administration, Resources, Software, Supervision, Validation, Visualization, Writing - Review \& Editing; Spotnitz M: Investigation, Methodology, Writing - Review \& Editing; Sena A: Data Curation, Formal Analysis, Investigation, Methodology, Software, Validation, Visualization, Writing - Review \& Editing; Shah N: Investigation, Methodology, Project Administration, Resources, Supervision, Writing Review \& Editing; Suchard M: Conceptualization, Data Curation, Funding Acquisition, Investigation, Methodology, Project Administration, Resources, Software, Supervision, Visualization, Writing - Review \& Editing; Chan You S: Conceptualization, Data Curation, Formal Analysis, Funding Acquisition, Investigation, Methodology, Project Administration, Resources, Software, Visualization, Writing - Review \& Editing; Hripcsak G: Conceptualization, Formal Analysis, Funding Acquisition, Investigation, Methodology, Project 
Administration, Resources, Software, Supervision, Visualization, Writing - Review \& Editing; Ryan P: Conceptualization, Data Curation, Formal Analysis, Funding Acquisition, Investigation, Methodology, Project Administration, Resources, Software, Supervision, Visualization, Writing - Review \& Editing; Morales D: Conceptualization, Formal Analysis, Funding Acquisition, Investigation, Methodology, Project Administration, Resources, Software, Supervision, Validation, Visualization, Writing - Original Draft Preparation, Writing - Review \& Editing

Competing interests: Dr. Verhamme works for a research department who received/receives unconditional research grants from Pfizer/Boehringer Ingelheim, Yamanouchi, Novartis, GSK, Chiesi, Amgen, UCB, J\&J none of which are related to the content of this work; Ms. Kostka reports consulting fees from National Institutes of Health NCATS, outside the submitted work; and during the 36 months prior to publication, Ms. Kostka was an employee of IQVIA Inc (a commercial entity); Dr. Prieto-Alhambra reports grants and other from AMGEN, grants, non-financial support and other from UCB Biopharma, grants from Les Laboratoires Servier, outside the submitted work; and Janssen, on behalf of IMI-funded EHDEN and EMIF consortiums, and Synapse Management Partners have supported training programmes organised by DPA's department and open for external participants; Dr. Blacketer reports and full-time employee of Janssen R\&D and a stockholder of Johnson \& Johnson; Dr. DuVall reports grants from Anolinx, LLC, grants from Astellas Pharma, Inc, grants from AstraZeneca Pharmaceuticals LP, grants from Boehringer Ingelheim International GmbH, grants from Celgene Corporation, grants from Eli Lilly and Company, grants from Genentech Inc., grants from Genomic Health, Inc., grants from Gilead Sciences Inc., grants from GlaxoSmithKline PLC, grants from Innocrin Pharmaceuticals Inc., grants from Janssen Pharmaceuticals, Inc., grants from Kantar Health, grants from Myriad Genetic Laboratories, Inc., grants from Novartis International AG, grants from Parexel International Corporation through the University of Utah or Western Institute for Veteran Research, outside the submitted work; Dr. Nyberg reports other from AstraZeneca, outside the submitted work; Dr. Posada reports grants from National Library of Medicine, during the conduct of the study; Dr. Rijnbeek reports grants from Innovative Medicines Initiative, from Janssen Research and Development, during the conduct of the study; Dr. Sena reports and full-time employee of Janssen R\&D and a stockholder of Johnson \& Johnson; Dr. Shah reports grants from National Library of Medicine, during the conduct of the study; Dr. Suchard reports grants from US National Institutes of Health, grants from US Department of Veterans Affairs, during the conduct of the study; grants from US Food \& Drug Administration, personal fees from Janssen Research \& Development, outside the submitted work; Dr. Hripcsak reports grants from US National Institutes of Health, during the conduct of the study; grants from Janssen Research, outside the submitted work; Dr. Ryan reports and is employee of Janssen Research and Development and shareholder of Johnson \& Johnson; Dr. Morales is supported by a Wellcome Trust Clinical Research Development Fellowship (Grant 214588/Z/18/Z) and reports grants from Chief Scientist Office (CSO), grants from Health Data Research UK (HDR-UK), grants from National Institute of Health Research (NIHR), and Tenovus outside the submitted work.

Grant information: The European Health Data \& Evidence Network has received funding from the Innovative Medicines Initiative 2 Joint Undertaking (JU) under grant agreement No 806968. The JU receives support from the European Union's Horizon 2020 research and innovation programme and EFPIA; This research received partial support from the National Institute for Health Research (NIHR) Oxford Biomedical Research Centre (BRC), US National Institutes of Health, US Department of Veterans Affairs, Janssen Research \& Development, and IQVIA; The University of Oxford received funding related to this work from the Bill \& Melinda Gates Foundation (Investment ID INV-016201 and INV-019257); IDIAPJGol received funding from the Health Department from the Generalitat de Catalunya with a grant for research projects on SARS-CoV-2 and COVID-19 disease organized by the Direcció General de Recerca i Innovació en Salut; DPA receives funding from NIHR Academy in the form of an NIHR Senior Research Fellowship. The views and opinions expressed are those of the authors and do not necessarily reflect those of the Clinician Scientist Award programme, NIHR, United States Department of Veterans Affairs or the United States Government, NHS, or the Department of Health, England; DRM is supported by a Wellcome Trust Clinical Research Development Fellowship (Grant 214588/Z/18/Z, https://doi.org/10.35802/214588); and DMM is funded by Health Data Research-UK.

The funders had no role in study design, data collection and analysis, decision to publish, or preparation of the manuscript.

Copyright: $\odot 2022$ Moreno-Martos D et al. This is an open access article distributed under the terms of the Creative Commons Attribution License, which permits unrestricted use, distribution, and reproduction in any medium, provided the original work is properly cited.

How to cite this article: Moreno-Martos D, Verhamme K, Ostropolets A et al. Characteristics and outcomes of COVID-19 patients with COPD from the United States, South Korea, and Europe [version 1; peer review: 1 approved with reservations] Wellcome Open Research 2022, 7:22 https://doi.org/10.12688/wellcomeopenres.17403.1

First published: 24 Jan 2022, 7:22 https://doi.org/10.12688/wellcomeopenres.17403.1 


\section{Introduction}

Severe acute respiratory syndrome coronavirus 2 (SARS-CoV-2) has infected over 200 million patients and resulted in more than 4.2 million deaths worldwide as of April 2021'. Coronavirus disease 2019 (COVID-19) can lead to severe lung injury and pneumonia, acute kidney injury, cardiovascular complications, and death. The symptoms and complications of COVID-19 have been compared to seasonal influenza resulting in national policy measures classifying chronic obstructive pulmonary disease (COPD) patients as high risk and advising them to take additional protective measures ${ }^{2}$. The prevalence of identified COPD among COVID-19 patients has ranged from $0.8 \%$ to $38 \%$ in the literature depending upon the cohort studied ${ }^{3}$. Whilst some studies suggest that the prevalence of COPD among COVID-19 patients may be lower than the prevalence of COPD in the general population COPD is still considered a risk factor for severe COVID-19 disease ${ }^{4}$.

Estimates for the prevalence of COPD among COVID-19 patients typically come from small, single-centre hospitalised cohorts and examine a limited range of patient characteristics and outcomes $^{3}$. Larger comparisons from geographically diverse cohorts that also include patients with milder COVID-19 illness provide a more compelling picture and improve generalisability. Viral respiratory tract infections are common triggers for exacerbations resulting in increased morbidity and mortality yet it is uncertain how often people with COPD with COVID-19 present with exacerbations ${ }^{5,6}$.

The aim of this study was to perform a large-scale, federated network, descriptive characterization study reporting the demographics, comorbidities, and outcomes of COPD patients with COVID-19 at the point of diagnosis and hospitalisation.

\section{Methods}

\section{Ethical approval}

All the data partners received Institutional Review Board (IRB) approval or exemption. STARR-OMOP had approval from IRB Panel \#8 (RB-53248) registered to Leland Stanford Junior University under the Stanford Human Research Protection Program (HRPP). The use of VA data was reviewed by the Department of Veterans Affairs Central Institutional Review Board (IRB), was determined to meet the criteria for exemption under Exemption Category 4(3), and approved for Waiver of HIPAA Authorization. The research was approved by the Columbia University Institutional Review Board as an OHDSI network study. The use of SIDIAP was approved by the Clinical Research Ethics Committee of the IDIAPJGol (project code: 20/070-PCV). The use of CPRD was approved by the Independent Scientific Advisory Committee (ISAC) (protocol number 20_059RA2). The use of IQVIA OpenClaims and IPCI was exempted from IRB approval for COVID-19 research.

\section{Study design}

The Characterizing Health Associated Risks and Your Baseline Disease In SARS-COV-2 (CHARYBDIS) study is a multinational cohort study using retrospective electronic health records and claims data on COVID-19 patients from three continents, the North America (US), Europe, and Asia ${ }^{7}$. All data for were standardized to the Observational Medical Outcomes Partnership (OMOP) Common Data Model (CDM) ${ }^{8,9}$. The Charybdis protocol and source code is available via open access (https://github.com/ohdsi-studies/Covid19CharacterizationCharybdis $)^{10}$.

\section{Data sources}

Of the nineteen databases available on $28^{\text {th }}$ November 2020 , 13 that had a minimum sample size of 140 COVID-19 patients with COPD were included. This minimum threshold was considered appropriate to estimate the prevalence of a previous condition or 30-day risk of an outcome affecting $10 \%$ of the study population. Supplementary Figure S1 presents the database selection process for this study ${ }^{11}$.

Data from the United States included: the University of Colorado Anschuz Medical Campus Health Data Compass (CUAMC HDC), the Columbia University Irving Medical Center data warehouse (CUIMC), HealthVerity, Stanford Medicine Research Data Repository (STARR-OMOP), IQVIA Open Claims, Optum de-identified Electronic Health Record Dataset and the United States Department of Veterans Affairs (VA-OMOP). Data from South Korea included the Health Insurance Review \& Assessment Service (HIRA) database. Data from Europe included the Spanish Information System for Research in Primary Care (SIDIAP) database; the Dutch Integrated Primary Care Information (IPCI) database, LPD (Longitudinal Patients Database) France, LPD Italy and the UK Clinical Practice Research Datalink (CPRD). Further information about databases considered for inclusion is contained in Appendix $1^{11}$.

Study participants and follow-up

COVID-19 cohorts: Two non-mutually exclusive cohorts were defined (Appendix 2) ${ }^{11}$. COVID-19 patients in the diagnosed cohort were defined as patients having a clinical diagnosis and/or positive test for SARS-CoV-2 from outpatient or inpatient records. In the diagnosed cohort, the index date was the earliest date of COVID-19 diagnosis or a first positive test. COVID-19 patients in the hospitalized cohort were defined as patients with a hospitalization episode and a clinical diagnosis of COVID-19 or positive SARS-CoV-2 test within 21 days prior to admission and up to the end of hospitalization. This time window was chosen to include patients with a diagnosis prior to hospitalization and to allow for delays in recording of test results. In the hospitalized cohort, the index date was the day of hospitalization.

All patients were required to have at least a year of observation time prior to index date. Patients were followed from the index date to the earliest of the studied outcome, end of follow-up (30 days after index date), end of data capture, or death.

COPD definition: COPD was defined as either: a) an occurrence of a COPD diagnosis code any time on or before the 
COVID-19 index date or b) a prescription or administration of COPD medications within the year prior to index date in patients older than or equal to 55 years (Appendix 3$)^{11}$. We excluded patients with a diagnosis of asthma prior to the COPD diagnosis to avoid misclassification with asthma. Codes used to define these cohorts have been previously described ${ }^{12,13}$ and are included in the Appendix ${ }^{11}$.

\section{Baseline characteristics}

Conditions and procedures were identified within 1 to 365 to days prior to the index date using Systematized Nomenclature of Medicine (SNOMED CT) codes with all descendent codes included codes mapped from local source vocabularies. We report pre-specified demographics and conditions related to COPD and COVID-19. Other conditions analysed as part of the larger CHARYBDIS project are reported here (https://data.ohdsi. org/Covid19CharacterizationCharybdis/).

COPD exacerbation was defined by a COPD exacerbation code at index date in databases with disease codes for exacerbation. The following medications were identified within 1 to 30 days prior to index date to characterise how patients were recently managed prior to the COVID-19 index date: systemic corticosteroids, inhaled corticosteroids (ICS), short-acting beta2-agonists (SABA), long-acting beta2-agonists (LABA), short-acting muscarinic antagonists (SAMA), long-acting antimuscarinic antagonists (LAMA), methylxanthines, mucolytics, oxygen therapy, antibiotics (beta-lactam penicillins, macrolides, fluoroquinolones), acetaminophen, nonsteroidal anti-inflammatory drugs (NSAIDs), and opioids. Medication use was calculated using drug eras that began starting on the date of the first drug exposure and ended on the observed end date of the last concatenated medication record, with a grace period of 30 days between medication records which allowed for sequential medication records to be considered as a continuous drug era.

\section{Outcomes}

We identified the following outcomes within 30 days following the index date: death, use of intensive services (identified as a recorded invasive mechanical ventilation and/or a tracheostomy and/or extracorporeal membrane oxygenation procedure), acute respiratory distress syndrome (ARDS), acute renal failure syndrome (ARFS), cardiac arrhythmia, heart failure, pulmonary oedema, myocardial infarction, sepsis, bleeding, venous thromboembolism (VTE), pulmonary embolism (PE) and stroke (ischaemic and haemorrhagic).

\section{Analysis}

A common analytical code for CHARYBDIS was run locally in each database. Only aggregate results from each database were then shared. We report the number and proportion by sociodemographics, history of comorbidities, and commonly used medications in each population with $95 \%$ confidence intervals (CI) calculated using the Wilson score method. Standardised mean differences (SMD) were calculated to aid comparison between study cohorts. We used $\mathrm{R}$ version 3.6.0 for data visualization. All the data partners obtained Institutional Review Board (IRB) approval or exemption to conduct this study, as required.

\section{Results}

\section{Prevalence of COPD}

The study included 934,778 COVID-19 patients in the diagnosed cohort (84.0\% from US and $16.0 \%$ from European databases) and 177,201 COVID-19 patients in the hospitalized cohort (87.5\% from US, $8.8 \%$ from European and $3.7 \%$ from South Korean databases). The observed prevalence of COPD in the diagnosed cohort ranged from $3.8 \%$ (95\% CI 3.5-4.1) in data from France to $22.7 \%$ (95\% CI 22.4-23.0) in the US (overall median $7.7 \%$ ) (Table 1). The observed prevalence of COPD in COVID-19 patients in the hospitalized cohort ranged from $1.9 \%$ (95\%CI 1.6-2.2) in data from South Korea to $44.0 \%$ (95\%CI 43.1-45.0) in the US (overall median 20.9\%). Among databases contributing to both COVID-19 cohorts, the prevalence of COPD was greater in hospitalized than in the diagnosed COVID-19 cohorts. COPD exacerbation at presentation ranged from $<0.8 \%$ to $6.4 \%(95 \% \mathrm{CI} 4.8-8.5)$ in the diagnosed cohort (median $4.1 \%$ ), and from $1.3 \%(95 \% \mathrm{CI} 0.6-2.8)$ to $12.0 \%$ (95\% CI 8.8-16.2) amongst those in the hospitalized cohort (median 7.7\%) (Table 2).

\section{Demographics}

In the hospitalized cohort, COPD patients with COVID-19 were more commonly male (range $46.8 \%$ to $58.5 \%$, overall median $54.5 \%$ ) (Supplementary Table S1) ${ }^{11}$. However, there was less consistent sex difference amongst patients in the diagnosed cohort (Supplementary Table S2) ${ }^{11}$. Whilst in VA-OMOP $96.7 \%$ of hospitalized patients and $94.6 \%$ of diagnosed patients were male, this was expected due to the population demographics with data predominantly originating from male veterans. In both cohorts, COPD patients with COVID-19 had a similar distribution of age and were more commonly older than 65 years $(\text { Supplementary Figure S2 and S3) })^{11}$.

\section{Baseline comorbidities}

In the diagnosed COPD cohort, the most prevalent comorbidities included obesity (median 49.1\%), cardiovascular disease (median 63.2\%), hypertension (median 72.4\%), chronic kidney disease (CKD) (median 29.8\%) and type 2 diabetes mellitus (T2DM) (median 35.9\%) (Table 3). Compared to those in the diagnosed cohort, the hospitalized COPD cohort had a greater prevalence of cardiovascular comorbidities, T2DM and CKD although these differences were typically modest (Table 4, Figure 1, Supplementary Figure S3) ${ }^{11}$.

\section{Medication use}

Systemic corticosteroid use in the 30 days prior to index date ranged from $5.1 \%$ (95\%CI $3.7-7.1)$ to $26.4 \%$ (95\%CI 21.4 32.1 ) in the diagnosed cohort, and from $7.5 \%$ (95\%CI 6.3-8.9) 


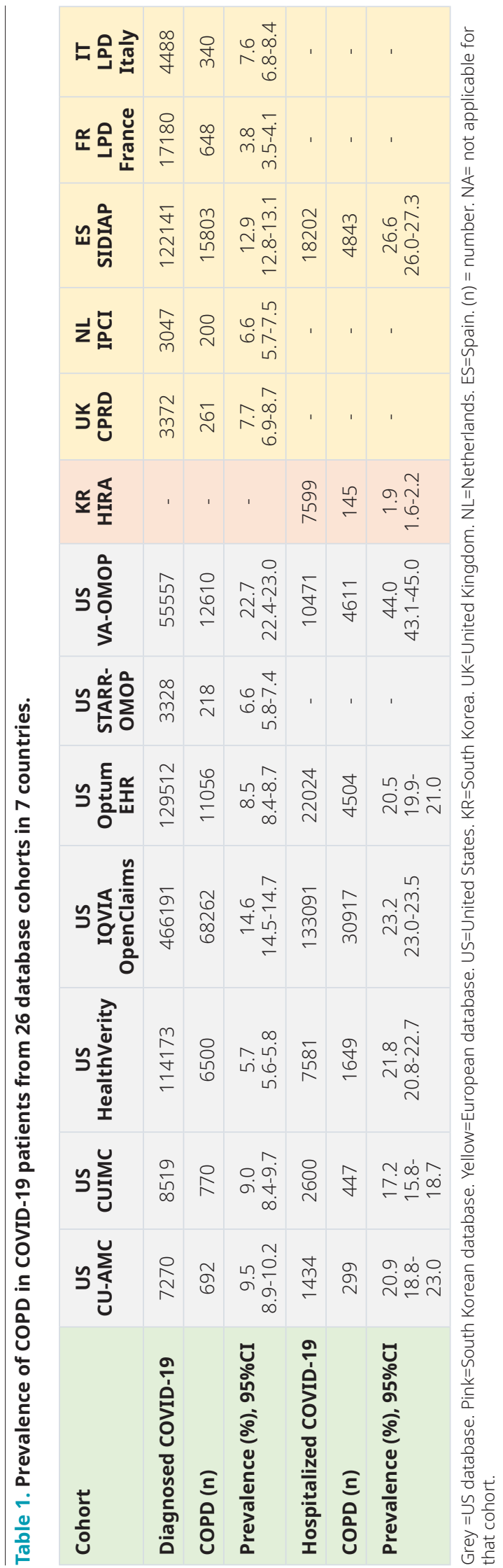


Table 2. Prevalence of COPD exacerbation in COVID-19 patients.

\begin{tabular}{|c|c|c|c|c|c|c|c|c|c|c|c|}
\hline Cohort & $\begin{array}{l}\text { US } \\
\text { CU-AMC }\end{array}$ & $\begin{array}{l}\text { US } \\
\text { CUIMC }\end{array}$ & $\begin{array}{c}\text { US } \\
\text { HealthVerity }\end{array}$ & $\begin{array}{c}\text { US } \\
\text { IQVIA } \\
\text { OpenClaims }\end{array}$ & $\begin{array}{l}\text { US } \\
\text { Optum } \\
\text { EHR }\end{array}$ & $\begin{array}{l}\text { US } \\
\text { STARR- } \\
\text { OMOP }\end{array}$ & $\begin{array}{c}\text { US } \\
\text { VA- } \\
\text { OMOP }\end{array}$ & $\begin{array}{c}\text { KR } \\
\text { HIRA }\end{array}$ & $\begin{array}{c}\text { UK } \\
\text { CPRD }\end{array}$ & $\begin{array}{l}\text { ES } \\
\text { SIDIAP }\end{array}$ & $\begin{array}{c}\text { FR } \\
\text { LPD } \\
\text { France }\end{array}$ \\
\hline $\begin{array}{l}\text { Diagnosed COVID-19 } \\
\text { Prevalence (\%), 95\%CI }\end{array}$ & $\begin{array}{c}6.4 \\
4.8-8.5\end{array}$ & $\begin{array}{c}1.9 \\
1.1-3.1\end{array}$ & $\begin{array}{c}3.7 \\
3.3-4.2\end{array}$ & $\begin{array}{c}5.0 \\
4.8-5.2\end{array}$ & $\begin{array}{c}6.2 \\
5.8-6.7\end{array}$ & $\begin{array}{c}4.1 \\
2.2-7.6\end{array}$ & $\begin{array}{c}2.9 \\
2.6-3.2\end{array}$ & - & $<1.9$ & $\begin{array}{l}1.8 \\
1.6-2.0\end{array}$ & $<0.8$ \\
\hline $\begin{array}{l}\text { Hospitalized COVID-19 } \\
\text { Prevalence (\%), 95\%CI }\end{array}$ & $\begin{array}{c}12.0 \\
8.8-16.2\end{array}$ & $\begin{array}{c}1.3 \\
0.6-2.8\end{array}$ & $\begin{array}{c}8.6 \\
7.3-10.1\end{array}$ & $\begin{array}{c}7.7 \\
7.4-8.0\end{array}$ & $\begin{array}{c}10.8 \\
9.9-11.7\end{array}$ & - & $\begin{array}{c}5.5 \\
4.9-6.2\end{array}$ & $<3.4$ & - & $\begin{array}{c}3.2 \\
2.7-3.7\end{array}$ & - \\
\hline
\end{tabular}

*No data on COPD exacerbations recorded for IPCI and LDP Italy. Grey =US database. Pink=South Korean database. Yellow=European database. US=United States. KR=South Korea. UK=United Kingdom. NL=Netherlands. ES=Spain.

to $28.4 \%$ (95\% CI 23.6-33.8) in the hospitalized cohort (Table 5 and Supplementary Table S3) ${ }^{11}$. Corresponding numbers for inhaled corticosteroid (ICS) use ranged from 5.3\% $(95 \% \mathrm{CI}$ $3.4-8.27 .7)$ to $44.8 \%$ (95\% CI 38.9-50.9), and from $7.6 \%$ (95\%CI $5.5-10.4$ ) to $33.7 \%$ (95\%CI 32.4-35.0) respectively (Figure 2). LABA use was more frequent than LAMA use. Macrolides were the most commonly prescribed antibiotics in the 30 days before index date in the US, French, and Italian databases while betalactam penicillins were more frequently prescribed in the South Korean, UK, Spanish and Dutch databases. Acetaminophen and NSAIDs were commonly prescribed to COPD patients, with use of both being more prevalent in the hospitalized cohort.

\section{Outcomes}

The proportion of hospitalized COVID-19 patients requiring intensive services varied from $5.5 \%$ (95\% CI 4.5-6.7) to $30.8 \%$ (95\% CI 25.8-36.2) (median 17.7\%). Amongst hospitalized COPD patients with COVID-19, the most common 30-day outcomes included ARDS (median 45.9\%), ARFS (median 45.9\%), cardiac arrhythmia (median 29.6\%), heart failure (median 14.6\%) and sepsis (median 16.9\%). Outcomes were more common in the hospitalised cohort than the diagnosed patients (Figure 3). (Table 6 and Supplementary Table S4) ${ }^{11}$. Among COPD patients with COVID-19 in the hospitalized cohort, 30-day mortality ranged from $7.6 \%(95 \% \mathrm{CI} 6.9-8.4)$ to $32.2 \%$ (95\% CI 28.0-36.7) (medium 21.4\%), whilst in the diagnosed cohort 30 -day mortality ranged from $3.7 \%(95 \%$ CI $3.4-4.1)$ to $24.9 \%$ (95\% CI 20.0-30.5) (median 15.6\%) (Table 7).

\section{Discussion}

COPD prevalence among patients with COVID-19 was 1.5- to 3 -fold greater among those hospitalized than among those in the diagnosed cohort. Studies from China have reported the lowest observed COPD prevalence in COVID-19 patients with rates as low of $0.8 \%{ }^{3}$. In contrast, COPD prevalence appears greater in European and US COVID-19 study populations. We similarly observed a low COPD prevalence among COVID-19 patients from South Korea compared to other countries, which may reflect differences in the baseline prevalence of COPD in each country. It could also relate to differences in how health care systems responded to the pandemic, for example whether people with COPD were considered high risk and given advice on risk reduction measures and shielding.

COVID-19 patients with COPD in both cohorts had a similar age distribution with the proportion of men being consistently higher in the hospitalized cohort. Increasing age, male gender and a history of cardiovascular disease are established risk factors for severe COVID-19 ${ }^{14-20}$. We similarly observed a high prevalence of cardiometabolic comorbidities among COPD patients with COVID-19 from both cohorts. This includes arrythmia, which increases the risk from azithromycin and hydroxychloroquine use as treatment of COVID-19, particularly when prescribed in combination but also may be related to atrial fibrillation being prevalent within patients with $\mathrm{COPD}^{21,22}$.

Although exacerbation at presentation was recorded more commonly among hospitalized patients, overall exacerbation prevalence was relatively low. Further studies are required to formally assess to what degree typical exacerbations of COPD are a presenting feature of COVID-19 in people with COPD.

There have been safety concerns over the role of ICS with reports of worse COVID-19 outcomes associated with ICS use $^{23,24}$. Whilst our study was not designed to formally assess this, we saw no large differences in ICS use between the cohorts as might be expected if use was associated with a large risk. Indeed, early clinical trials suggest that use of inhaled budesonide use may be beneficial ${ }^{25}$. The increased use of acetaminophen, opioids and NSAIDs among hospitalized patients also suggests greater symptomatic illness. Whilst similar safety concerns with NSAID use have also emerged, recent studies have not found them to be harmful ${ }^{26,27}$. 


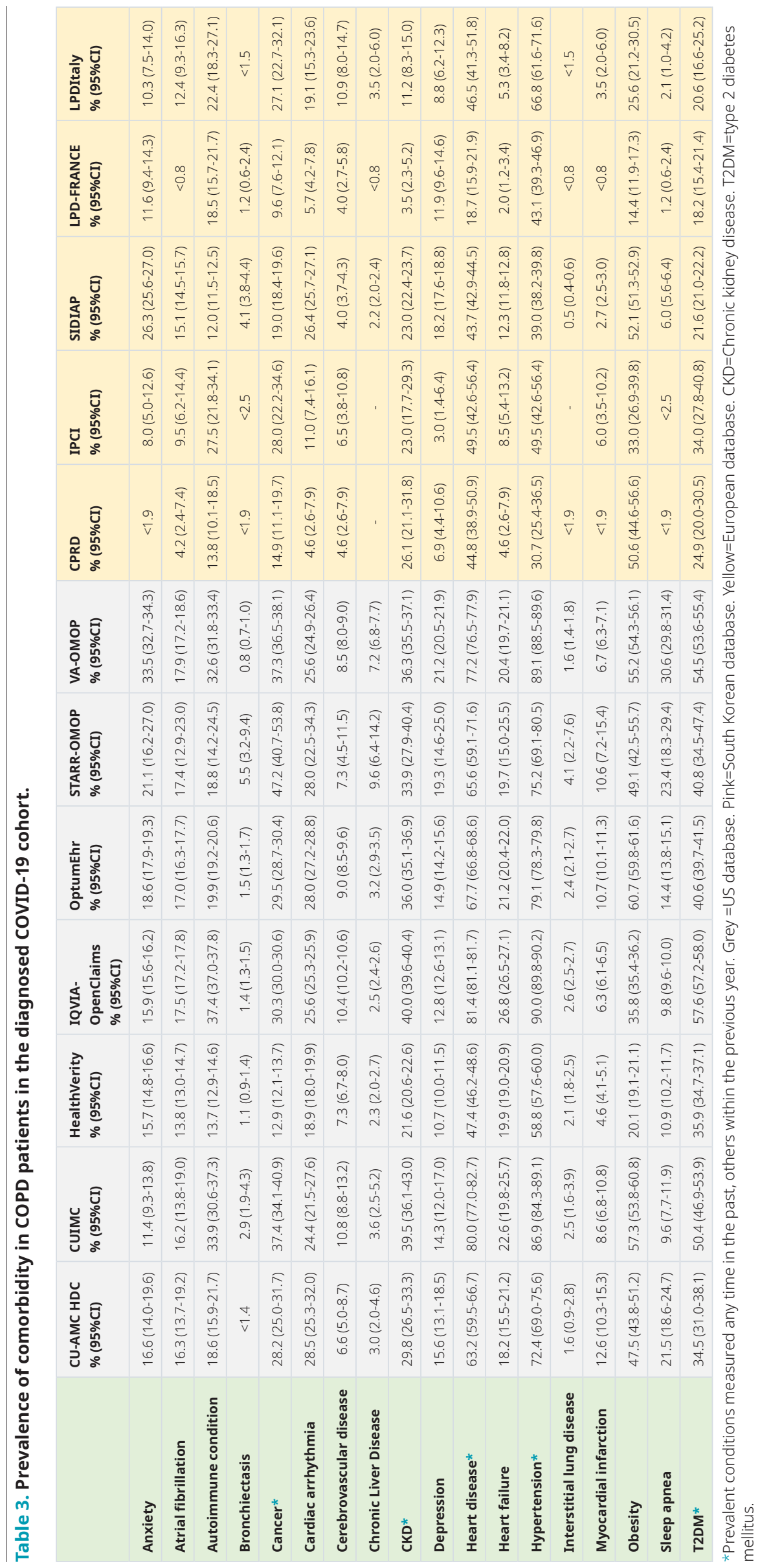




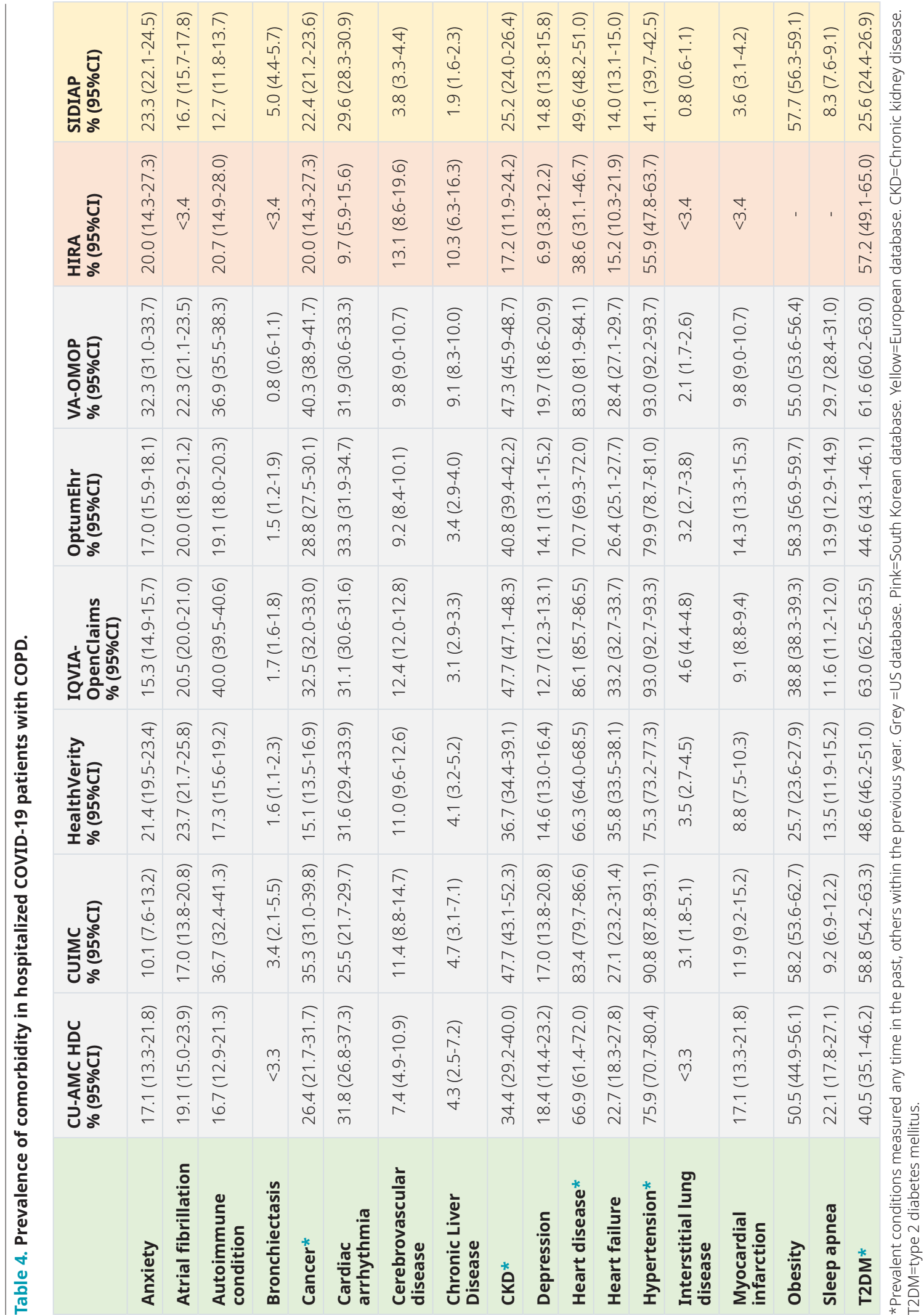




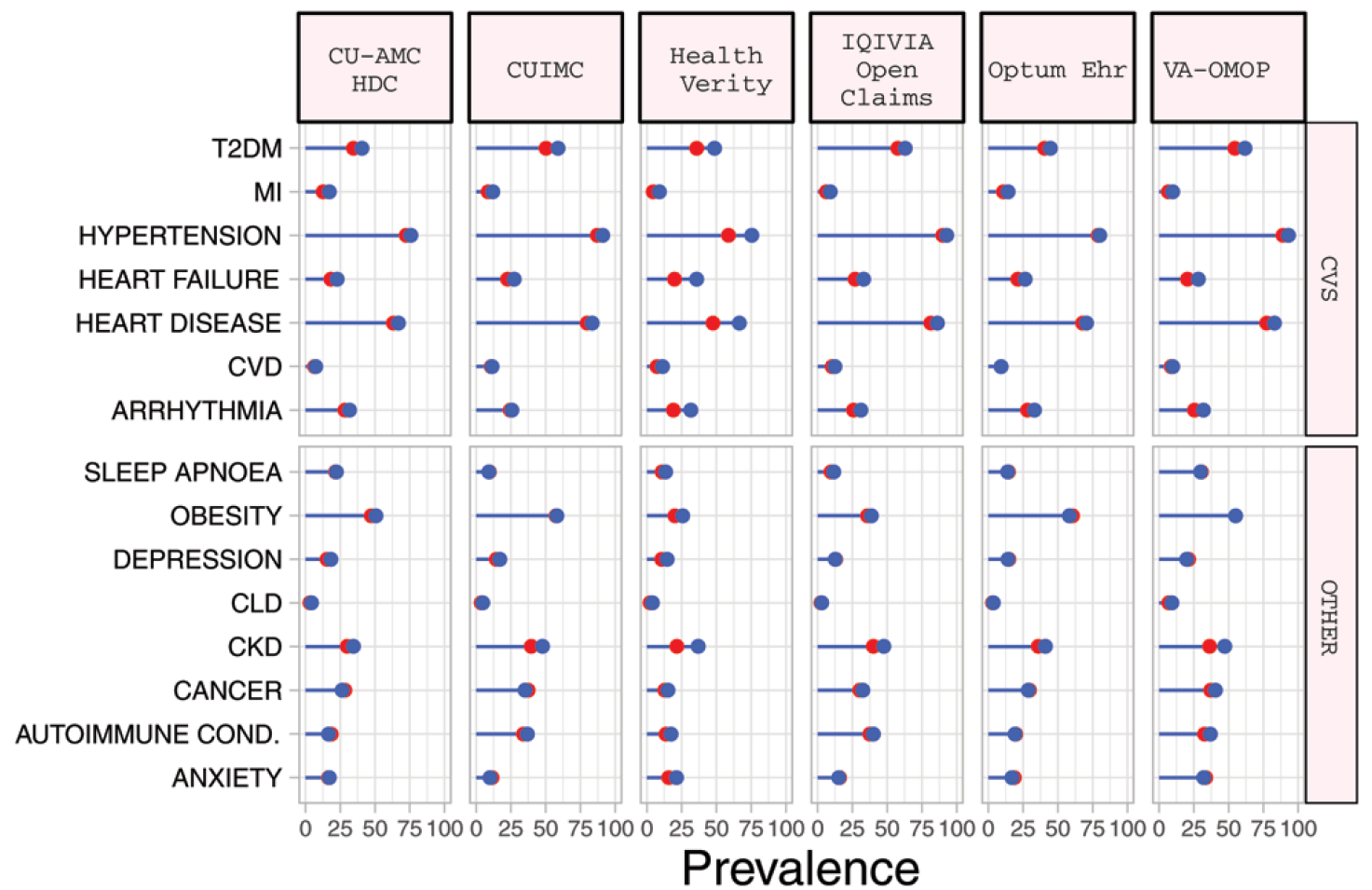

Figure 1. Prevalence of comorbidities among COPD patients with COVID-19 who have been diagnosed (red) and hospitalized (blue). *Databases contributing patients to both the diagnosed and hospitalized cohorts. T2DM=Type 2 diabetes mellitus. MI=myocardial

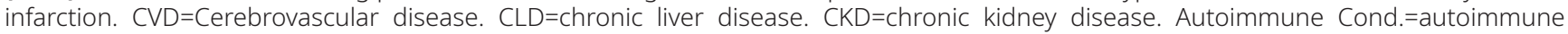
conditions. CVS=Cardiovascular.

The most common 30-day outcomes were ARDS, ARFS, arrhythmia, sepsis and heart failure suggesting that a multi-organ approach is required for COVID-19 clinical management. As expected, hospitalized COPD patients had a higher prevalence of poor health outcomes. However, it is useful to understand this risk among a cohort that includes milder cases at an earlier stage of the illness despite having similar levels of baseline comorbidity.

\section{Strength and limitations}

A strength of this study is the federated analysis allowing large numbers of patients to be characterized between countries, which overcomes some of the limitations of smaller single centre studies and potential heterogeneity that can occur by applying different methods of analysis. Furthermore, information on a large number of additional patient characteristics relating to conditions and treatment are also available online. The study has several limitations, however. First, the study is dependent upon the data captured by each database that could underestimate the prevalence of some characteristics. For example, prior systemic corticosteroid use ranged from $7.5 \%$ to
$28.4 \%$ in the hospitalized cohort and $5.1 \%$ to $26.4 \%$ in the diagnosed cohort. The prevalence of systemic corticosteroid use was slightly higher than the prevalence of an exacerbation diagnosis. Whilst this suggests that some underestimation in exacerbation recording may have occurred, other indications for systemic corticosteroid in patients with COPD exist that could also explain the higher systemic corticosteroids use. Second, despite using a standardized data structure and method of analysis, heterogeneity between databases was still observed and it was not possible to determine whether this related to differences in clinical care compared to differences in the type of database. Lastly, our study was descriptive in nature and was not designed to examine causal associations. However, this type of evidence has still contributed to support the understanding COVID-19 in patients with COPD and could be useful as hypothesis generating for future studies ${ }^{28}$.

\section{Conclusions}

COVID-19 patients with COPD are a vulnerable group with a high prevalence of other risk factors for severe COVID-19. No large differences in ICS use were seen between COPD patients 


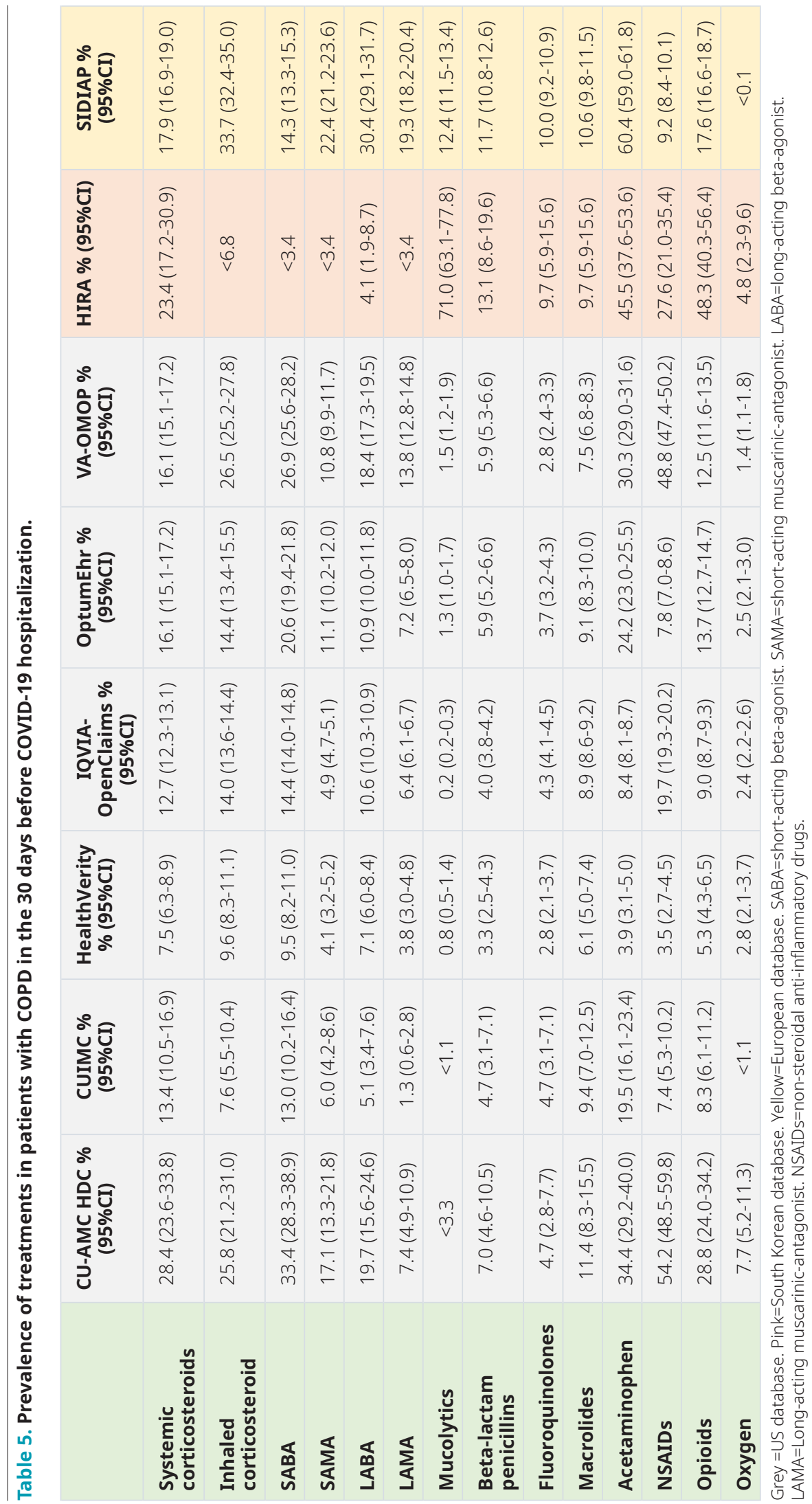




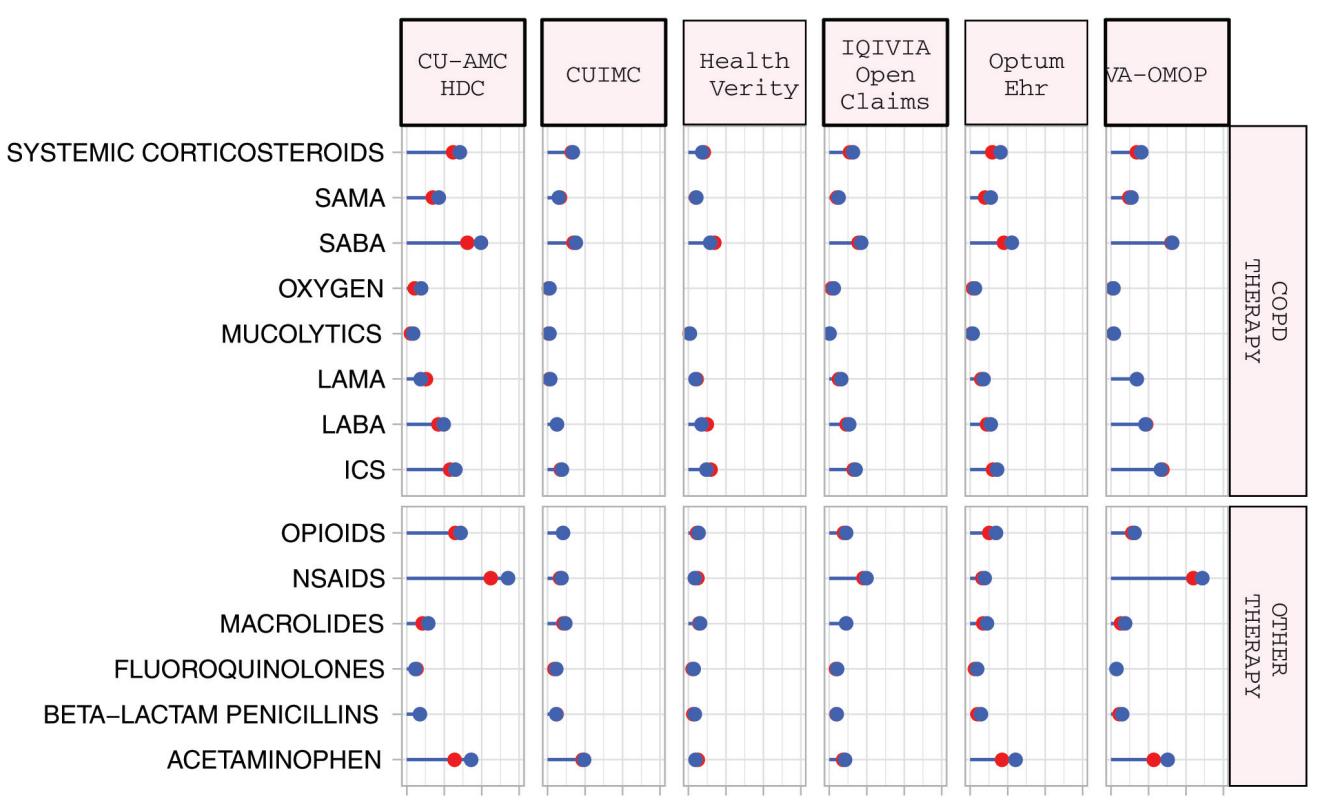

020406002040600204060020406002040600204060

Prevalence

Figure 2. Prevalence of treatments among COPD patients with COVID-19 who have been diagnosed (red) and hospitalized (blue). *Databases contributing patients to both the diagnosed and hospitalized cohorts. SAMA=short-acting muscarinic antagonist. SABA=short-acting beta2-agonist. LAMA=Long-acting muscarinic antagonist. LABA=Long-acting beta2-agonist. ICS=inhaled corticosteroids. NSAIDs=non-steroidal anti-inflammatory drugs.

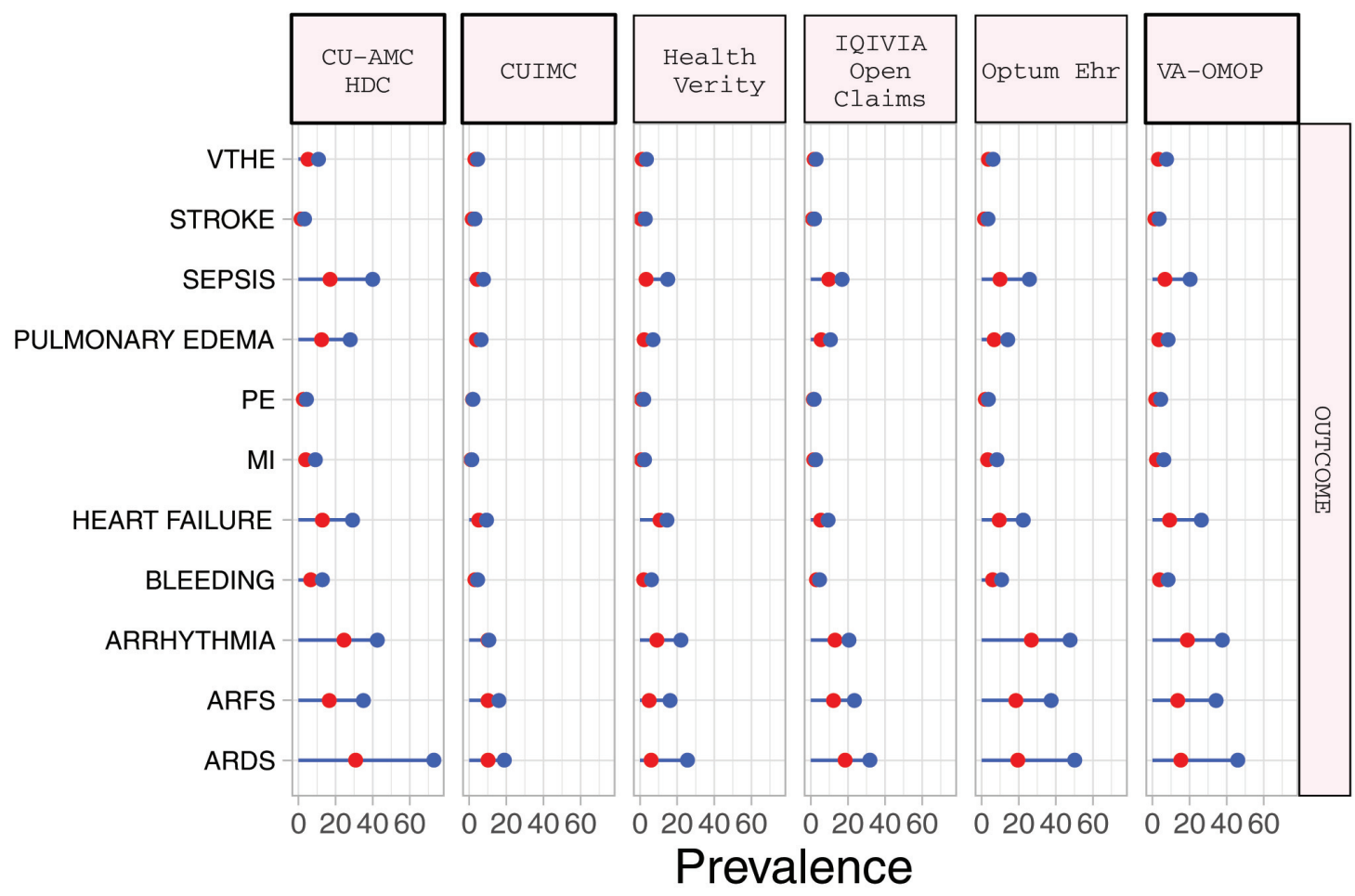

Figure 3. Prevalence of outcomes among COPD patients with COVID-19 who have been diagnosed (red) and hospitalized (blue). *Databases contributing patients to both the diagnosed and hospitalized cohorts. VTHE=venous thromboembolism. PE=pulmonary edema. MI=myocardial infarction. ARFS=Acute renal failure syndrome. ARDS=Acute respiratory distress syndrome. 


\begin{tabular}{|c|c|c|c|c|c|c|c|}
\hline & $\begin{array}{c}\text { CU-AMC HDC } \\
\%(95 \% \mathrm{CI})\end{array}$ & $\begin{array}{l}\text { CUIMC \% } \\
\text { (95\%CI) }\end{array}$ & $\begin{array}{c}\text { HealthVerity } \\
\%(95 \% \mathrm{CI})\end{array}$ & $\begin{array}{c}\text { IQVIA- } \\
\text { OpenClaims } \\
\%(95 \% \mathrm{CI})\end{array}$ & $\begin{array}{l}\text { OptumEhr \% } \\
\text { (95\%CI) }\end{array}$ & $\begin{array}{l}\text { VA-OMOP \% } \\
(95 \% \mathrm{CI})\end{array}$ & $\begin{array}{l}\text { HIRA \% } \\
(95 \% \text { CI })\end{array}$ \\
\hline $\begin{array}{l}\text { Intensive } \\
\text { services }\end{array}$ & $30.8(25.8-36.2)$ & NA & $5.5(4.5-6.7)$ & $9.9(9.6-10.2)$ & $17.7(16.6-18.8)$ & $18.4(17.3-19.5)$ & $9.7(5.9-15.6)$ \\
\hline ARDS & $72.9(67.6-77.6)$ & $19.0(15.6-22.9)$ & $25.6(23.5-27.8)$ & 31.7 (31.2-32.2) & $50.2(48.7-51.7)$ & $45.9(44.5-47.3)$ & $<3.4$ \\
\hline ARFS & $35.1(29.9-40.7)$ & $16.1(13.0-19.8)$ & $16.3(14.6-18.2)$ & $23.5(23.0-24.0)$ & $37.4(36.0-38.8)$ & $34.4(33.0-35.8)$ & $<3.4$ \\
\hline $\begin{array}{l}\text { Cardiac } \\
\text { arrhythmia }\end{array}$ & $48.2(42.6-53.8)$ & $14.8(11.8-18.4)$ & 15.5 (13.8-17.3) & $14.9(14.5-15.3)$ & $37.4(36.0-38.8)$ & $37.8(36.4-39.2)$ & $7.6(4.3-13.1)$ \\
\hline $\begin{array}{l}\text { Heart } \\
\text { failure }\end{array}$ & $29.1(24.2-34.5)$ & $9.4(7.0-12.5)$ & $14.6(13.0-16.4)$ & $9.3(9.0-9.6)$ & $22.4(21.2-23.6)$ & $26.4(25.1-27.7)$ & $4.8(2.3-9.6)$ \\
\hline $\begin{array}{l}\text { Pulmonary } \\
\text { edema }\end{array}$ & $27.8(23.0-33.1)$ & $6.5(4.6-9.2)$ & $7.0(5.9-8.3)$ & $10.5(10.2-10.8)$ & $14.2(13.2-15.2)$ & $8.3(7.5-9.1)$ & $4.1(1.9-8.7)$ \\
\hline $\begin{array}{l}\text { Myocardial } \\
\text { infarction }\end{array}$ & $9.0(6.3-12.8)$ & $1.3(0.6-2.8)$ & $2.4(1.8-3.3)$ & $2.6(2.4-2.8)$ & $8.3(7.5-9.1)$ & $6.1(5.4-6.8)$ & $<3.4$ \\
\hline Sepsis & $40.1(34.7-45.8)$ & $7.6(5.5-10.4)$ & $14.9(13.3-16.7)$ & $16.9(16.5-17.3)$ & $25.8(24.5-27.1)$ & $20.3(19.2-21.5)$ & $5.5(2.8-10.5)$ \\
\hline Bleeding & $13.0(9.7-17.3)$ & $4.5(2.9-6.8)$ & $6.2(5.1-7.5)$ & $4.8(4.6-5.0)$ & $10.9(10.0-11.8)$ & $8.3(7.5-9.1)$ & $6.2(3.3-11.4)$ \\
\hline VThE & $10.7(7.7-14.7)$ & $4.5(2.9-6.8)$ & $3.5(2.7-4.5)$ & $2.8(2.6-3.0)$ & $6.3(5.6-7.0)$ & $7.6(6.9-8.4)$ & - \\
\hline PE & $4.3(2.5-7.2)$ & $2.0(1.0-3.8)$ & $2.0(1.4-2.8)$ & $1.9(1.8-2.1)$ & $3.8(3.3-4.4)$ & $4.5(3.9-5.1)$ & - \\
\hline Stroke & $3.3(1.8-6.0)$ & $3.1(1.8-5.1)$ & $2.9(2.2-3.8)$ & $2.0(1.8-2.2)$ & $3.4(2.9-4.0)$ & $3.6(3.1-4.2)$ & $<3.4$ \\
\hline
\end{tabular}

Grey $=$ US database. Pink=South Korean database. Yellow=European database. SABA=short-acting beta-agonist. ARDS=acute respiratory distress syndrome. ARFS=acute renal failure syndrome. VThe=venous thromboembolic disease. $\mathrm{PE}=$ pulmonary embolism.

\begin{tabular}{|c|c|c|c|c|c|c|c|c|}
\hline Cohort & $\begin{array}{l}\text { CU-AMC \% } \\
(95 \% \mathrm{CI})\end{array}$ & $\begin{array}{l}\text { CUIMC \% } \\
(95 \% \mathrm{CI})\end{array}$ & $\begin{array}{c}\text { Optum } \\
\text { EHR \% } \\
(95 \% \mathrm{CI})\end{array}$ & $\begin{array}{l}\text { VA-OMOP } \\
\%(95 \% \mathrm{CI})\end{array}$ & $\begin{array}{l}\text { HIRA \% } \\
(95 \% C I)\end{array}$ & $\begin{array}{l}\text { CPRD \% } \\
(95 \% \mathrm{CI})\end{array}$ & $\begin{array}{l}\text { IPCI \% } \\
(95 \% C I)\end{array}$ & $\begin{array}{l}\text { SIDIAP \% } \\
(95 \% \mathrm{CI})\end{array}$ \\
\hline $\begin{array}{l}\text { Diagnosed } \\
\text { COVID-19 }\end{array}$ & $\begin{array}{c}11.6 \\
(9.4-14.2)\end{array}$ & $\begin{array}{c}18.8 \\
(16.2-21.7)\end{array}$ & $\begin{array}{c}3.7 \\
(3.4-4.1)\end{array}$ & $\begin{array}{c}8.3 \\
(7.8-8.8)\end{array}$ & - & $\begin{array}{c}24.9 \\
(20.0-30.5)\end{array}$ & $\begin{array}{c}23.5 \\
(18.2-29.8)\end{array}$ & $\begin{array}{c}15.6 \\
(15.0-16.2)\end{array}$ \\
\hline $\begin{array}{l}\text { Hospitalized } \\
\text { COVID-19 }\end{array}$ & $\begin{array}{c}25.8 \\
(21.2-31.0)\end{array}$ & $\begin{array}{c}32.2 \\
(28.0-36.7)\end{array}$ & $\begin{array}{c}7.6 \\
(6.9-8.4)\end{array}$ & $\begin{array}{c}17.6 \\
(16.5-18.7)\end{array}$ & $\begin{array}{c}16.6 \\
(11.4-23.5)\end{array}$ & - & - & $\begin{array}{c}21.4 \\
(20.3-22.6)\end{array}$ \\
\hline
\end{tabular}

Grey =US database. Pink=South Korean database. Yellow=European database

with milder and more severe COVID-19 although further studies are required to confirm or refute this. COPD patients expe- rience a high morbidity and mortality from COVID-19 and require a multi-organ approach to clinical management. 


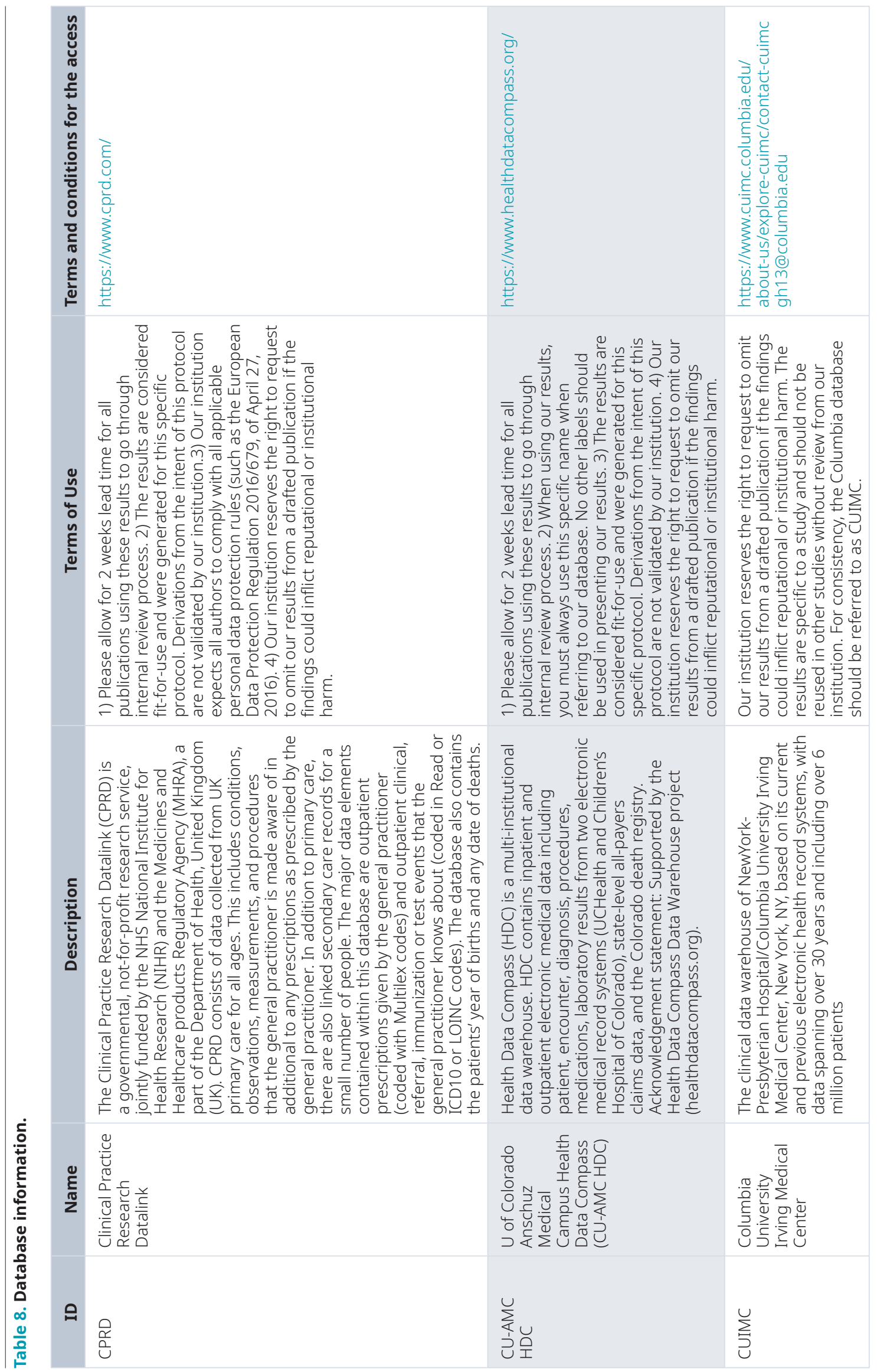




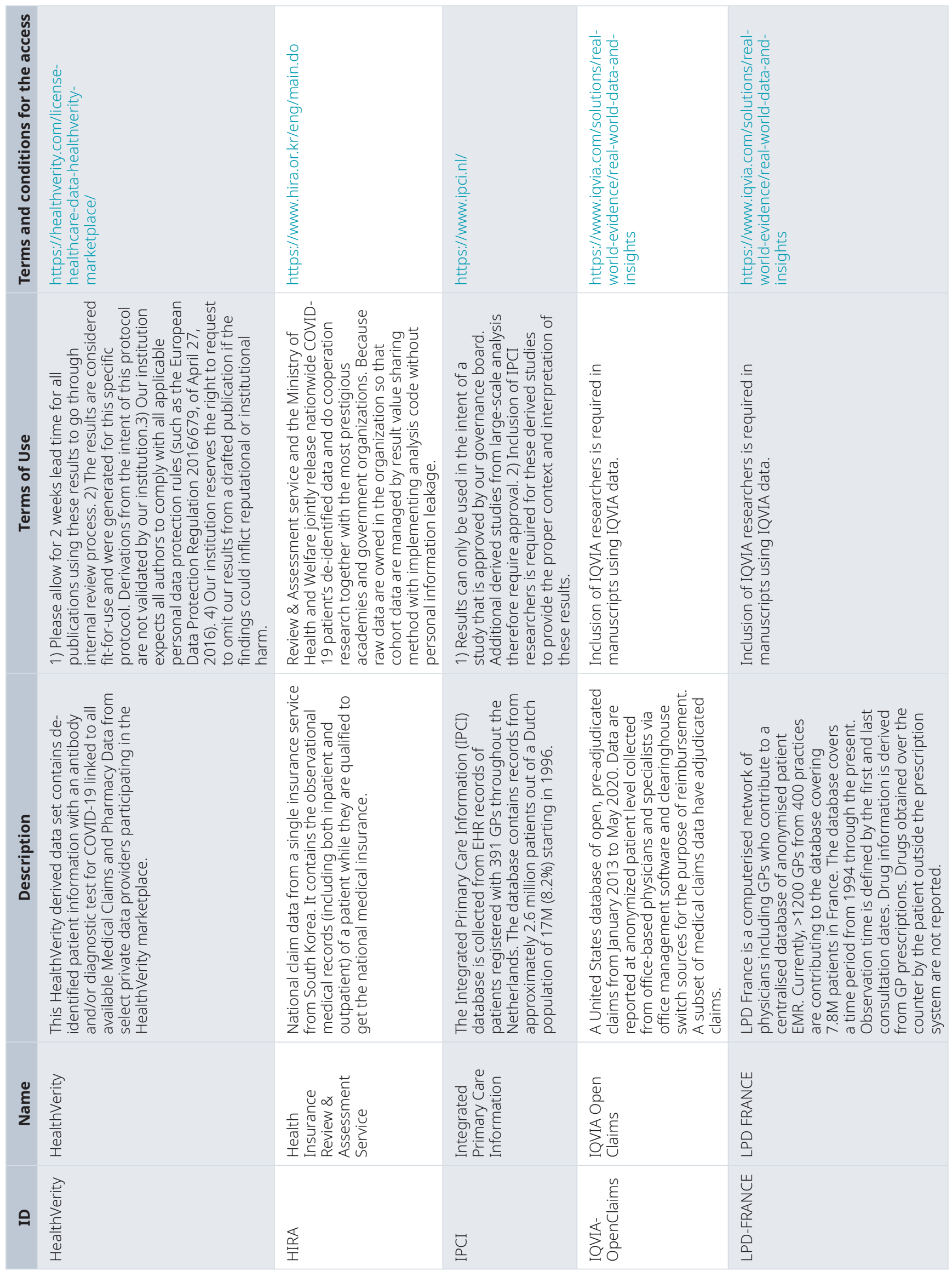




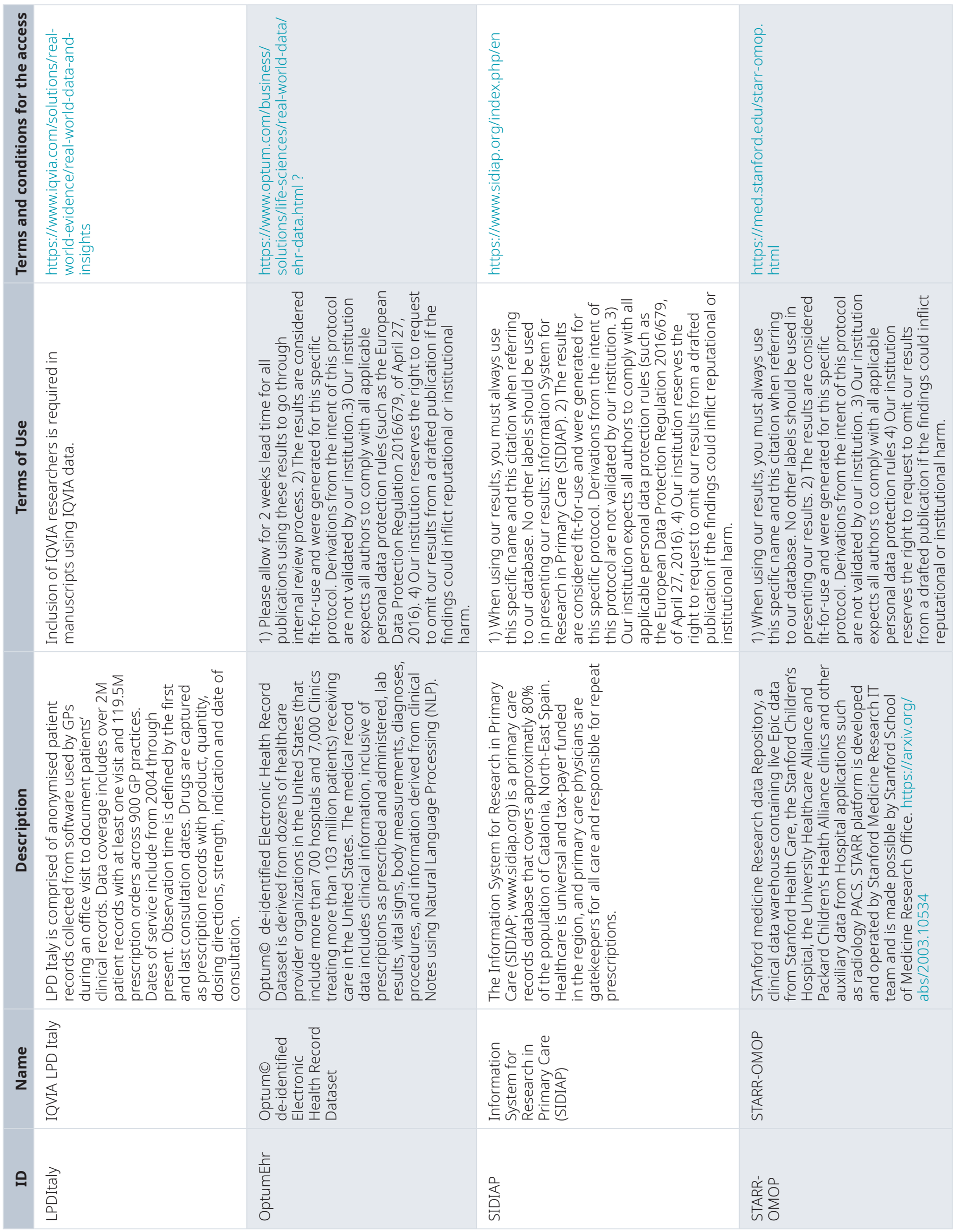




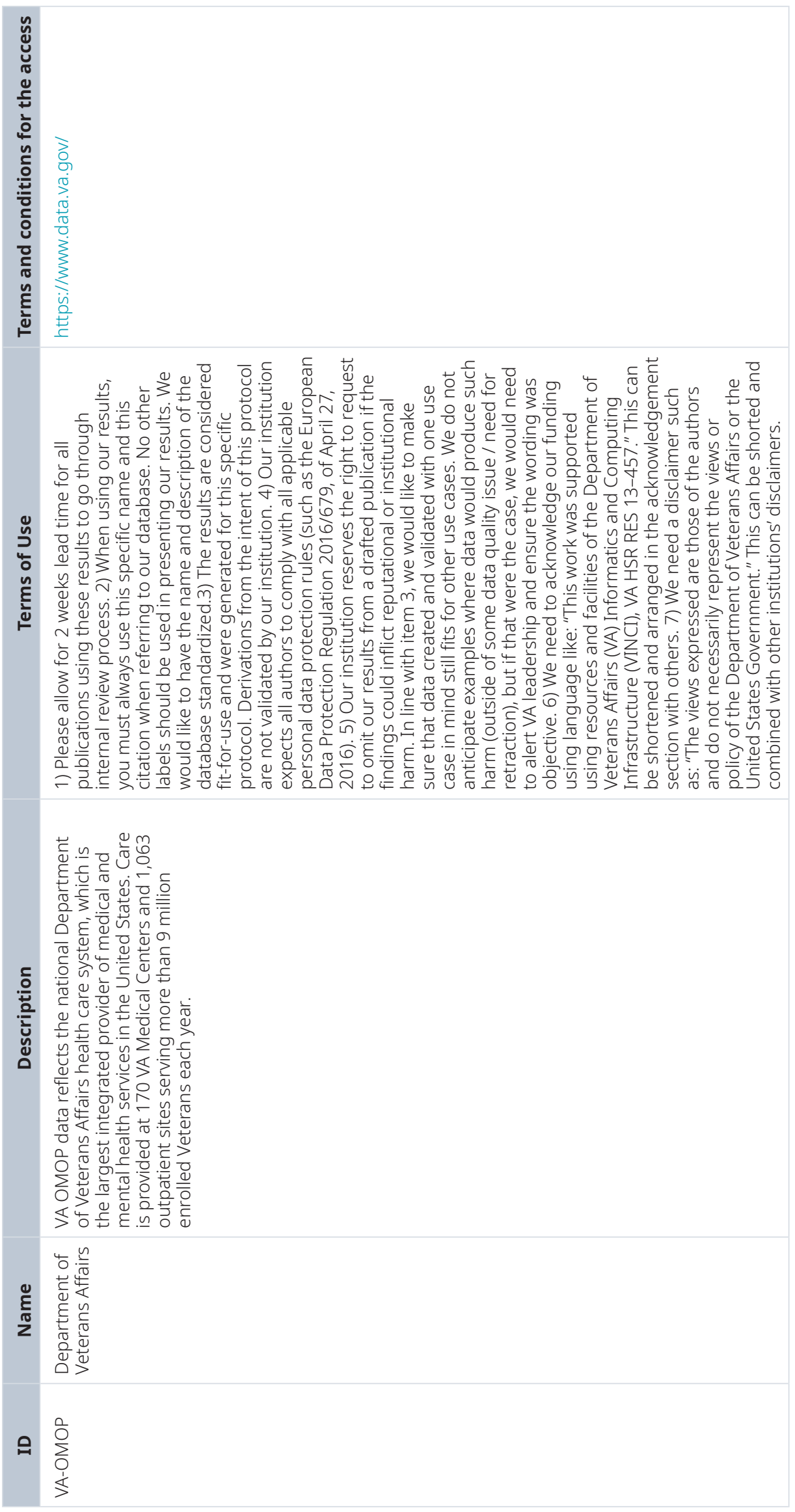




\section{Data availability}

Underlying data

Raw data from each database cannot be shared due to data privacy and governance requirements but raw data could be accessed according to the terms and conditions of each data source. The data source information including the terms and conditions for data access can be found in Table 8. Analyses were performed locally in compliance with all applicable data privacy laws. All aggregate data has been made freely available for public inquiry (https://data.ohdsi.org/Covid19CharacterizationCharybdis/).

All analytic code and result sets have been made available (https://github.com/ohdsi-studies/Covid19CharacterizationCharybdis).

Archived analysis code as at time of publication: https://doi. org/10.5281/zenodo.577926429. Code is available under the terms of the Apache License 2.0.

\section{Extended data}

Zenodo: Characteristics and outcomes of COVID-19 patients with COPD from the United States, South Korea, and Europe - Supplementary Materials. https://doi.org/10.5281/ zenodo. $5780046^{11}$.

This project contains the following extended data:

- Supplementary Table S1. Age and gender distribution of hospitalized COVID-19 patients with COPD.

- Supplementary Table S2. Age and gender distribution of diagnosed COVID-19 patients with COPD.

- Supplementary Table S3. Prevalence of treatments in patients with COPD in the 30 days before COVID-19 diagnosis.
- Supplementary Table S4. Prevalence of outcomes in diagnosed COVID-19 patients with COPD with 95\%CI.

- Supplementary Figure S1. Flow chart showing database selection.

- Supplementary Figure S2. Prevalence of age and gender among COPD patients with COVID-19 who have been diagnosed and hospitalized.

- Supplementary Figure S3. Comparison of characteristics between COPD patients with COVID-19 in the diagnosed and hospitalized cohorts by SMD.

- Appendix 1. Overview of Data Sources Screened for Eligibility and Contributing Results

- Appendix 2. Definitions and codes used to identify COVID-19

- Appendix 3. Definitions and codes used to identify COPD patients

Data are available under the terms of the Creative Commons Attribution 4.0 International Public License (Attribution 4.0 International).

\section{Acknowledgements}

We would like to acknowledge the patients who suffered from or died of this devastating disease, and their families and carers. We would also like to thank the healthcare professionals involved in the management of COVID-19 during these challenging times, from primary care to intensive care units. Furthermore, we acknowledge the work and dedication of the 350 participants from 30 nations in the March 2020 OHDSI COVID-19 Virtual Study-a-thon, without whom this study could not have been realized including Liza Schilling for their active participation in the study execution.
1. Worldometer: COVID-19 CORONAVIRUS PANDEMIC. [cited 2021 Apr 20]. Reference Source

2. British Thoracic Society: BTS guidance for health care professionals in relation to shielding. [cited 2020 Sep 20]. Reference Source

3. Leung JM, Niikura M, Yang CWT, et al.: COVID-19 and COPD. Eur Respir J. 2020; 56(2): 2002108.

PubMed Abstract | Publisher Full Text | Free Full Text

4. Alqahtani JS, Oyelade T, Aldhahir AM, et al.: Prevalence, Severity and Mortality associated with COPD and Smoking in patients with COVID-19: A Rapid Systematic Review and Meta-Analysis. PLoS One. 2020; 15(5): e0233147. PubMed Abstract | Publisher Full Text | Free Full Text

5. Wark PA, Tooze $M$, Powell $H$, et al.: Viral and bacterial infection in acute asthma and chronic obstructive pulmonary disease increases the risk of readmission. Respirology. 2013; 18(6): 996-1002. PubMed Abstract | Publisher Full Text | Free Full Text

6. Ko FW, Chan PK, Chan RWY, et al:: Molecular detection of respiratory pathogens and typing of human rhinovirus of adults hospitalized for exacerbation of asthma and chronic obstructive pulmonary disease. Respir
Res. 2019; 20(1): 210

PubMed Abstract | Publisher Full Text | Free Full Text

7. Prieto-Alhambra D, Kostka K, Duarte-Salles T, et al.: Unraveling CoviD19: a large-scale characterization of 4.5 million COVID-19 cases using CHARYBDIS. Res Sq. 2021; rs.3.rs-279400.

PubMed Abstract | Publisher Full Text | Free Full Text

8. Voss EA, Makadia R, Matcho A, et al.: Feasibility and utility of applications of the common data model to multiple, disparate observational health of the common data model to multiple, disparate observat PubMed Abstract | Publisher Full Text | Free Full Text

9. Hripcsak G, Duke JD, Shah NH, et al.: Observational Health Data Sciences and Informatics (OHDSI): Opportunities for Observational Researchers. Stud Health Technol Inform. 2015; 216: 574-8.

PubMed Abstract | Free Full Text

10. Sena A, Kostka K, Schuemie M, et al.: ohdsi-studies/ Covid19CharacterizationCharybdis: Charybdis v1.1.1 - Publication Package (Version v1.1.1). Zenodo. 2020; [cited 2020 Sep 16]. Publisher Full Text

11. Moreno-Martos D, Morales DR: Characteristics and outcomes of COVID-19 
patients with COPD from the United States, South Korea, and Europe Supplementary Materials. Zenodo. 2021; [cited 2021 Dec 14]. http://www.doi.org/10.5281/zenodo.5780046

12. Duarte-Salles T, Vizcaya D, Pistillo A, et al.: Baseline characteristics, management, and outcomes of 55,270 children and adolescents diagnosed with COVID-19 and 1,952,693 with influenza in France, Germany, Spain, South Korea and the United States: an international network cohort study. medRxiv. 2020: 2020.10.29.20222083. PubMed Abstract | Publisher Full Text | Free Full Text

13. Kohler J, Kostka K, Makadia R, et al.: Using Real World Data to Understand HIV and COVID-19 in the U.S.A. and Spain: Characterizing Co-Infected Patients Across the Care Cascade. medRxiv. 2020; 2020.11.10.20229401. Publisher Full Text

14. Du RH, Liang LR, Yang CQ, et al.: Predictors of Mortality for Patients with COVID-19 Pneumonia Caused by SARS-CoV-2: A Prospective Cohort Study. Eur Respir J. 2020; 55(5): 2000524. PubMed Abstract | Publisher Full Text | Free Full Text

15. Verity R, Okell LC, Dorigatti I, et al.: Estimates of the severity of coronavirus disease 2019: a model-based analysis. Lancet Infect Dis. 2020; 20(6): 669-677. PubMed Abstract | Publisher Full Text | Free Full Text

16. Richardson S, Hirsch JS, Narasimhan M, et al.: Presenting Characteristics, Comorbidities, and Outcomes Among 5700 Patients Hospitalized With COVID-19 in the New York City Area. JAMA. 2020; 323(20): 2052-2059. PubMed Abstract | Publisher Full Text | Free Full Text

17. Yang $X, Y u Y, X u$ J, et al.: Clinical course and outcomes of critically ill patients with SARS-CoV-2 pneumonia in Wuhan, China: a single-centered, retrospective, observational study. Lancet Respir Med. 2020; 8(5): 475-481. PubMed Abstract | Publisher Full Text | Free Full Text

18. Yancy CW: COVID-19 and African Americans. JAMA. 2020; 323(19): 1891-1892. PubMed Abstract | Publisher Full Text

19. Rimmer A: Covid-19: Two thirds of healthcare workers who have died were from ethnic minorities. BMJ. 2020; 369: $\mathrm{m} 1621$. PubMed Abstract | Publisher Full Text

20. Burn E, You SC, Sena AG, et al.: Deep phenotyping of 34,128 adult patients hospitalised with COVID-19 in an international network study. Nat Commun. 2020; 11(1): 5009.

PubMed Abstract | Publisher Full Text | Free Full Text

21. Lane JCE, Weaver J, Kostka K, et al.: Risk of hydroxychloroquine alone and in combination with azithromycin in the treatment of rheumatoid arthritis: a multinational, retrospective study. Lancet Rheumatol. 2020; 2(11): e698-e711. PubMed Abstract | Publisher Full Text | Free Full Text

22. Axfors C, Schmitt AM, Janiaud P, et al.: Mortality outcomes with hydroxychloroquine and chloroquine in COVID-19 from an international collaborative meta-analysis of randomized trials. Nat Commun. 2021; 12(1): 2349.

PubMed Abstract | Publisher Full Text | Free Full Text

23. Schultze A, Walker AJ, MacKenna B, et al.: Risk of COVID-19-related death among patients with chronic obstructive pulmonary disease or asthma prescribed inhaled corticosteroids: an observational cohort study using the OpenSAFELY platform. Lancet Respir Med. 2020; 8(11): 1106-1120. PubMed Abstract | Publisher Full Text | Free Full Text

24. Aveyard P, Gao M, Lindson N, et al.: Association between pre-existing respiratory disease and its treatment, and severe COVID-19: a population cohort study. Lancet Respir Med. 2021; 9(8): 909-923. PubMed Abstract | Publisher Full Text | Free Full Text

25. Ramakrishnan S, Nicolau DV Jr, Langford B, et al.: Inhaled budesonide in the treatment of early COVID-19 (STOIC): a phase 2, open-label, randomised controlled trial. Lancet Respir Med. 2021; 9(7): 763-772.

PubMed Abstract | Publisher Full Text | Free Full Text

26. Lund LC, Kristensen KB, Reilev M, et al.: Adverse outcomes and mortality in users of non-steroidal anti-inflammatory drugs who tested positive for SARSCoV-2: A Danish nationwide cohort study. PLOS Med. 2020; 17(9): e1003308. PubMed Abstract | Publisher Full Text | Free Full Text

27. Wong AY, MacKenna B, Morton CE, et al.: Use of non-steroidal antiinflammatory drugs and risk of death from COVID-19: an OpenSAFELY cohort analysis based on two cohorts. Ann Rheum Dis. 2021; 80(7): 943-951. PubMed Abstract | Publisher Full Text | Free Full Text

28. Halpin DMG, Criner G], Papi A, et al.: Global Initiative for the Diagnosis, Management, and Prevention of Chronic Obstructive Lung Disease. The 2020 GOLD Science Committee Report on COVID-19 and Chronic Obstructive Pulmonary Disease. Am J Respir Crit Care Med. 2021; 203(1): 24-36. PubMed Abstract | Publisher Full Text | Free Full Text

29. Sena A, Kostka K, Schuemie M, et al.: DavidMorenoMartos/ Covid19Characterization Charybdis: v1.4.3 (v1.4.3). Zenodo. 2021; [cited 2021 Dec 14].

http://www.doi.org/10.5281/zenodo.5779264 


\section{Open Peer Review}

\section{Current Peer Review Status: ?}

\section{Version 1}

Reviewer Report 31 January 2022

https://doi.org/10.21956/wellcomeopenres.19241.r48211

(C) 2022 Kisiel M. This is an open access peer review report distributed under the terms of the Creative Commons Attribution License, which permits unrestricted use, distribution, and reproduction in any medium, provided the original work is properly cited.

\section{Marta A. Kisiel}

Department of Medical Sciences, Environmental and Occupational Medicine, Uppsala University, Uppsala, Sweden

This study addressed an important topic, investigating COVID-19 patients with COPD. The study is based on several databases from different countries. The main conclusion was that there were more COPD patients in the hospitalised COVID-19 group than in the diagnosed COVID-19 group. The authors highlighted the limitation of heterogenicity of the cohorts. Also, the accuracy of COPD diagnosis in all included cohorts might be a limitation that should be added. The authors show other comorbidities like obesity, cardiovascular diseases and diabetes. It might be that association of COPD and hospitalised COVID-19 should be adjusted by other comorbidities.

The information on different cohorts is hard to find among all supplementary tables and might be organised in a more available form. As the authors should extend the list of study limitations.

The study should undergo a minor revision before it can be accepted.

Is the work clearly and accurately presented and does it cite the current literature? Yes

Is the study design appropriate and is the work technically sound? Partly

Are sufficient details of methods and analysis provided to allow replication by others? Partly

If applicable, is the statistical analysis and its interpretation appropriate? Yes

Are all the source data underlying the results available to ensure full reproducibility? Partly 
Are the conclusions drawn adequately supported by the results?

Yes

Competing Interests: No competing interests were disclosed.

Reviewer Expertise: Asthma, Occupational Lung Disease, Smal airways, Post covid

I confirm that I have read this submission and believe that I have an appropriate level of expertise to confirm that it is of an acceptable scientific standard, however I have significant reservations, as outlined above.

Author Response 18 Mar 2022

David Moreno Martos, University of Dundee, Dundee, UK

We thank the reviewer for their time in reviewing the manuscript. We agree it is entirely possible that some of the differences in outcomes between COVID-19 diagnosed and hospitalised patients may be as a result of other comorbidities. However, this study is descriptive in nature and hypothesis generating rather than intended to provide causal inference, which would be beyond the scope of the current study. We have now expanded the study limitations in the Discussion. Journal requirements preclude us to include supplementary material here although we have re-formatted the supplementary material document to improve clarity.

Competing Interests: No competing interests were disclosed. 